\title{
An electrophysiological study of errorless learning
}

\author{
Antoni Rodriguez-Fornells ${ }^{\mathrm{a}, \mathrm{b}}$, Christine Kofidis ${ }^{\mathrm{a}}$, Thomas F. Münte ${ }^{\mathrm{a}, *}$ \\ ${ }^{a}$ Department of Neuropsychology, Otto von Guericke University, Universitätsplatz 2, Gebäude 24, 39106 Magdeburg, Germany \\ ${ }^{\mathrm{b}}$ Research group in Cognitive Neuroscience, University of the Balearic Islands, Spain
}

Accepted 20 November 2003

\begin{abstract}
Errorless learning, i.e. learning under conditions that prevent the generation of false memory candidates, has been shown to lead to enhanced memory performance during retrieval compared to errorful, trial-and-error, learning. These two learning methods were implemented in a word-stem completion format and contrasted in young healthy subjects with stimulus-locked and response-locked eventrelated brain potentials (ERPs) being recorded during memory retrieval. Retrieval accuracy was enhanced for items studied under errorless conditions. Stimulus-locked ERPs showed a modulation of a right frontal effect that differed in amplitude and topography for items learned under errorful and errorless conditions. This effect is interpreted as reflecting post-retrieval processes. In the response-locked ERPs, a typical error-related negativity (ERN) was observed that was most prominent for false alarm trials in the errorless condition, of medium amplitude for hits and false alarms in the errorful condition, smaller for hits in the errorless condition and virtually absent for items correctly or incorrectly classified as new. We propose that the amplitude modulation of the ERN is related to the activity of an internal monitoring device checking the veridicality of a retrieved memory trace.
\end{abstract}

(C) 2004 Elsevier B.V. All rights reserved.

Theme: Motor systems and sensorimotor integration

Topic: Control of pasture and movement

Keywords: ERP; Memory; Error-related negativity; Errorless learning; Cognitive control

\section{Introduction}

One of the critical processes in human memory is the detection and elimination of memory errors during retrieval. That retrieval can be erroneous is illustrated by the numerous studies on false memories (see for a review Ref. [55]). Some authors have provided evidence for a self-monitoring or error-checking process, which evaluates the output of retrieval operations and tries to inhibit possible memory intrusions $[6,42,43,46,62,64]$. Moscovitch [42], for example, separated the memory retrieval component from the evaluation of its output. This evaluative process is thought to check the retrieved information for errors and is considered to be self-initiated, strategic, and effortful [43]. Burgess and Shallice [6] introduced a "memory editor" or monitoring stage as part of their supervisory attentional system, thus placing it

* Corresponding author. Fax: +49-391-671-1947.

E-mail address: thomas.muente@med.uni-magdeburg.de (T.F. Münte). in the context of executive control functions. The aim of this post-retrieval process is to verify the appropriateness of the retrieved information in a given context. Similar proposals have been made by Norman and Bobrow [45] and, more recently, by Koriat and Goldsmith [36]. The existence of an error-checking mechanism has been supported by several studies $[46,62,64]$. Its breakdown gives rise to confabulatory disorders $[46,62]$. Different neuroimaging studies $[1,26,27,65]$ have pointed to the right dorsolateral prefrontal cortex as supporting the errorchecking/monitoring process (for a review, see Ref. [59]).

In the present study, in order to further characterize the brain signatures of this executive control component of memory retrieval, we contrasted event-related brain potentials to items that had been learned under errorless and errorful conditions (cf. Ref. [3]).

\subsection{Errorless learning}

Learning often entails a trial-and-error approach (henceforth "errorful" learning, EF), i.e. a number of errors will be 
produced during the learning phase until the correct response is found. These errors are likely to cause interference and ultimately memory failures during subsequent retrieval attempts. In an animal study, Terrace [73] was the first to demonstrate that the number of memory errors during retrieval could be reduced by preventing the generation of wrong responses during the encoding phase (henceforth "errorless" learning, EL) (see also, Refs. [3,30,31,35,51, $53,66,69,70,80])$. A technique similar to the current study has been used by Baddeley and Wilson [3]: In the $E F$ condition, the initial letters of a word ("stem", e.g. F-L-O) are presented and subjects are encouraged to guess, which word the experimenter has in mind. After one or more "incorrect" guesses (e.g. flood, floor, flour), the experimenter indicates the correct completion (e.g. flower). The purpose of this procedure is to introduce errors during the learning phase. During EL learning, on the other hand, the designated correct word is directly provided to the subject at the beginning of each trial and, therefore, this learning method prevents possible incorrect guesses. In a study that compared amnesic patients with normal young subjects and normal elderly subjects, all three subject groups showed better recall after EL than EF learning. This differential effect was most pronounced in the amnesic group, which also had a lower overall performance. What is the reason for the increased memory performance after EL learning? Baddeley and Wilson [3] suggested that the EF condition might lead to more memory errors because the trial-anderror learning procedure enhances the level of activation of incorrect guesses, which then will compete with the activation of the correct item at retrieval. By contrast, the EL condition prevents such competition, because only the correct response gets activated during learning. The interference from multiple activated items after EF learning might be especially detrimental in subjects with memory impairment, as these rely on familiarity based decisions. Both correct and incorrect items are familiar in the errorful learning condition, and only the recollection of the specific aspects of the learning episode helps to keep these items apart.

The necessity to recollect the learning episode for items learned under EF but not under EL conditions places the EF/ EL paradigm in the context of source memory studies (see Refs. [33,34] for a review). According to the source-monitoring framework, monitoring processes are applied to old and new items in order to differentiate between them. These operations can be made explicit by asking the subjects to not only decide, whether a given item during retrieval is "new" or "old", but also to make a secondary decision for the old items that reveals knowledge about the encoding episode (e.g. had it been spoken by a male or female speaker?).

\subsection{Event-related brain potentials and memory}

In recognition memory paradigms, items, e.g. words, that have been encountered before and are classified as old are associated with different ERP waveforms than items that are "new". Across studies, three ERP effects distinguishing old and new items have been consistently observed: first a decrease of the amplitude of the N400 component (between 300 and $500 \mathrm{~ms}$ ); second, an increase of a parietal positive slow wave (between 500 and $800 \mathrm{~ms}$ ) that has been given different labels such as "late positive component" [16,17, $48-50,60]$, “P300" $[15,18]$, late positivity $[14,57,58]$ or "parietal old/new effect" [56]. Finally, most relevant for the present investigation, different frontally distributed effects have been described, most often taking the form of a right frontal positivity in the $800-1900 \mathrm{~ms}$ range $[16,17,63$, $77,78]$. With regard to the right frontal positivity, the fact that it has been observed in paradigms that extend beyond simple recognition judgments and involve the retrieval of source information $[63,77,78]$ or require post-retrieval decision-making processes $[13,16,77,78]$ suggests that it could be related to monitoring functions. For example, in a source monitoring task, Wilding and Rugg [77] found a right frontal positivity for those items that were classified as new and attributed to the right voice (see also Refs. $[39,76,78])$. Consequently, this right-frontal ERP effect has been discussed as reflecting retrieval of specific perceptual information regarding the memory source, the fact that such effects have not been found consistently in source memory tasks $[63,79]$ casts some doubt on this association, however. Moreover, Raganath and Paller [52] described a left frontal ERP effect that they interpreted as being due to the requirement to retrieve perceptual detail. Finally, Donaldson and Rugg [14] described two frontal positivities, one early and bilateral, the other occurring later and showing a right-sided maximum, which were differentially related to their task manipulations.

\subsection{Electrophysiology of action monitoring}

Within the last 10 years, ERP investigations of executive processes have focused on error detection and action monitoring. By averaging time-locked to the motor response rather than to the stimulus-onset, a negative component has been isolated appearing immediately after committing errors which therefore has been labeled error-related negativity (ERN) $[19,22,23]$. A large part of the ERN can be explained by a source in the anterior cingulate cortex $[12,25,37]$. One model associates the ERN to an error-detection mechanism $[20,22]$, which compares an internal goal (a computed "best response") with the predicted consequences of the actual response. An internal "error signal" is generated if a mismatch is detected by the system. An alternative interpretation holds that the ERN merely reflects the degree of response conflict experienced by subjects $[5,10]$. This theory fits well with data showing ERNs or anterior cingulate activity for correct responses $[7,38,61,75]$ and responses showing a higher degree of motor conflict $[4,24,74]$. Thus, the ERN-conflict detection model points to the "evaluative" nature of the anterior cingulate cortex $[8,9]$. Thus, the ERN 
should be present when conflicting response alternatives are present, which suggests that it should be differentially affected by retrieval decisions for the different stimulus classes in the present study. Interestingly, Nessler and Mecklinger [44] were the first to use the ERN in a memory task. In their study, subjects studied words belonging two certain taxonomic categories (e.g. cosmetic articles, songbirds). During the retrieval test, these studied words were presented together with two classes of new words: so-called lure words, belonging to the same taxonomic categories as the studied items of that experimental block, and true new words not having any relationship to the study words. In the response-locked averages, the authors reported an ERN-like component for both true recognitions and false (i.e. lureword) recognition, with the effect being larger for the latter category. Interestingly, the distribution of the ERN-like component in the Nessler and Mecklinger [44] study was more posterior than the typical fronto-central distribution seen in other tasks.

\section{Method}

\subsection{Sample}

Fifteen right-handed volunteers (eight women) between 20 and 26 years of age (mean 24 years) were paid for their participation. All of them were native German speakers, neurologically healthy and had normal or corrected-tonormal vision.

\subsection{Task description and procedure}

The whole session comprised five study-phase/recognition-phase blocks as follows: Study phase: In each study phase 60 words had to be learned, which were pseudorandomly assigned to the EF or the EL condition. In a typical EF-trial, the following instructions were given by the experimenter sitting next to the subject: "I am thinking of a word that begins with the letters B-R-U. Can you tell me some words which begin with these letters...". A possible first answer could have been "Brust" (chest). Upon the first answer, the experimenter immediately required another guess. After guessing some words (usually 2-3), the experimenter told the subject which one of the guessed words was correct or, in case the subject had not produced the desired word, provided the correct answer. The subject then repeated the target word. In this example the possible "correct" candidates could have been "Brust" or "Bruder" (brother). Both of these words were produced with $34 \%$ probability in a recent German stem completion study (data courtesy Richardson-Klavehn and Düzel, unpublished). Other, lower probability candidates for this letter triplet could have been "Brunnen" (well, 13\%), "Brunst" (ardour, 6\%) or "Brutal" (brutal, 3\%). These words were not used in the scenarios of the retrieval phase.
For half of the subjects one high probability candidate was designated as correct (target), while for the other half of the subjects the second high probability candidate was used. For errorless trials (EL) the instructions were patterned after the following example: "I am thinking of a word that begins with $\mathrm{A}-\mathrm{N}-\mathrm{Z}$. This word is 'Anzeige' (advertiseement, 53\%)". The subject had to immediately repeat the target word. Notice that "Anzahl" (number, 28\%) could have been another high probability candidate (with regard to the stem completion results) but was neither mentioned nor guessed in this learning condition. However, this word was presented in the recognition phase as a "new word" for half of the subjects. The other half of the subjects had "Anzahl" as target in the EL condition with "Anzeige" being used as a new word during recognition.

Recognition phase: After a short rest period of 2 to 3 min, the recognition phase began during which ERPs were recorded. During each recognition phase, 120 words were presented one by one in the middle of a video monitor (random SOA 1500-2000 ms, rectangular distribution; 300 ms presentation time). Words were presented in white letters against a black background and subtended $0.5^{\circ}$ of visual angle in height and between $1^{\circ}$ and $3^{\circ}$ in width. For each word, subjects had to signal by pressing one of two buttons whether or not a word had been a "correct" target word during the study phase.

Stimulus selection: Two lists of 150 different three letterstems were used for the EF and EL conditions, respectively (see Appendix A). The stems selected had at least two highprobability candidates for completion (in all cases the sum of the probability of the two most probable candidates was larger than 0.56; for the chosen 300 stems and 600 word candidates, the mean probability of stem completion using the two most probable candidates was 0.76 ). The mean frequency of all two most probable candidate words was 42.4 per million as determined by the CELEX database [2]. Thus, for each three-letter stem two candidates were chosen and used to prepare fixed scenarios for the word recognition task. Two lists of 150 stems were prepared and assigned to the EF or EL condition. This assignment was counterbalanced across subjects. Mean stem completion probability for the two candidate words was 0.76 in both lists and the mean word frequencies of the candidate words were 45.4 and 39.5 per million. The assignment of the target candidate for any given stem was also balanced across subjects. All in all there were four learning lists for which candidates were systematically rotated. See the following table for an example: Example for assignment of candidate words to the learning lists

\begin{tabular}{lllll}
\hline Condition & List A & List B & List C & List D \\
\hline Errorless target & Brust & Bruder & Anzahl & Anzeige \\
Errorless non-target & Bruder & Brust & Anzeige & Anzahl \\
Errorful target & Anzeige & Anzahl & Bruder & Brust \\
Errorful non-target & Anzahl & Anzeige & Brust & Bruder \\
\hline
\end{tabular}


The word lists presented during the recognition test comprised 120 words, 30 "target" words from the EL and EF condition each plus the corresponding "non-target" candidate words. Five different pseudo-random scenarios were generated using these 120 words for every recognition phase. In each one the candidate words belonging to the same stem were separated by at least 15 intervening items.

\subsection{Electrophysiological recording}

ERPs were recorded from the scalp using tin electrodes mounted in an electrocap (Electro-Cap International) and located at 29 standard positions (Fp1/2, Fz, F7/8, F3/4, Fc1/ 2 Fc5/6, Cz, C3/4, T3/4, Cp1/2, Cp5/6, Pz, P3/4, T5/6, Po1/ 2 , O1/2). Biosignals were recorded against a reference electrode placed on the right mastoid and were re-referenced off-line to the mean of the activity at the two mastoid processes. Vertical eye movements were monitored by a bipolar montage. Electrode impedances were kept below 5 $\mathrm{k} \Omega$. The electrophysiological signals were filtered with a bandpass of $0.01-70 \mathrm{~Hz}$ (half-amplitude cut-offs) and digitized at a rate of $250 \mathrm{~Hz}$. Trials with base-to-peak electro-oculogram (EOG) amplitude of more than $50 \mu \mathrm{V}$, amplifier saturation, or a baseline shift exceeding $200 \mu \mathrm{V} / \mathrm{s}$ were automatically rejected off-line (percentage of rejected trials was $\sim 15 \%$ with no difference between conditions). Stimulus-locked ERPs were averaged for epochs of $1700 \mathrm{~ms}$ starting $100 \mathrm{~ms}$ prior to the stimulus. The factorial combination of learning condition (EF/EL), stimulus type (target/ non-target) and response (correct/incorrect) yielded eight different averages:

\begin{tabular}{ll}
\hline EF-Hits & correct recognition of target guesses \\
EF-Misses & non-recognized target guesses \\
EF-CR & correct rejection of target guesses \\
false alarms to non-target guesses & correct recognition of old words \\
EF-FA & non-recognized old words \\
EL-Hits & correct rejection of new words \\
EL-Misses & (non-target candidate words from \\
EL-CR("new words") & the EL condition) \\
& false alarms to new words \\
&
\end{tabular}

Notice that EL-CR is the only category comprising words new to the subject which were correctly classified as such. Therefore, this average will be used as a "baseline" against which the ERPs to the other words will be compared. In addition, response-locked averages starting $400 \mathrm{~ms}$ before and extending $624 \mathrm{~ms}$ beyond the buttonpress responses were obtained, again yielding eight different categories. Signal detection measures were used to evaluate learning performance [68]. In addition to the standard measures $d^{\prime}$ (accuracy) and beta (response bias), we also computed a measure of precision or "relevance" (ratio of hits and [hits plus false alarms]) used commonly to evaluate the proportion of retrieval items that are relevant [72]. The statistical analysis was performed using repeated measures designs as specified in the Results section. Target components for the evaluation of the ERPs were the N400 and the late positive component (LPC) in the stimulus-locked averages and the error-related negativity (ERN) in the response-locked average. Several three factor repeated measures ANOVAs were conducted for the evaluation of stimulus-locked ERPs (specified in each case in the Results section) and including (specified in each case) Type of stimuli (e.g. Hits, false alarms, etc.), Learning method (EF vs. EL learning), Hemisphere (right, left) and Anterior/Posterior position as within subject factors. The ANOVAs were conducted separately for data from the parasagittal locations (PS) (7 levels for anterior/posterior factor: $\mathrm{Fp} 1 / 2, \mathrm{~F} 3 / 4, \mathrm{FC} 1 / 2, \mathrm{C} 3 / 4, \mathrm{CP} 1 / 2, \mathrm{P} 3 / 4, \mathrm{PO} 1 / 2)$ and lateral (LAT) locations (5 levels for anterior/posterior, F7/ 8, FC5/6, T3/4, CP5/6, T5/6). For the midline locations $(\mathrm{MD}, \mathrm{Fz}, \mathrm{Cz}, \mathrm{Pz}$ ) only an Anterior/Posterior factor was included in the design. Statistical tests were carried out on mean amplitude measures in specified time-windows. To further investigate interactions including Type of stimuli and learning method, additional ANOVAs restricted to specific electrode sites were carried out.

For all statistical effects involving two or more degrees of freedom in the numerator, the Greenhouse-Geisser epsilon was used to correct for possible violations of the sphericity assumption [32]. The exact $P$-value after the correction will be reported. Tests involving electrode $\mathrm{x}$ condition interactions were carried out on data corrected using the vector normalization procedure [40].

\section{Results}

\subsection{Performance measures}

The performance measures are summarized in Table 1. The EF learning method elicited an increased number of hits

Table 1

Summary of performance measures

\begin{tabular}{lcccc}
\hline \multicolumn{2}{c}{ Hits } & Misses & Correct rejections & False alarms \\
\hline Percentage & $($ S.D.) & & & \\
Errorful & $69.0(13)$ & $30.0(13)$ & $45.2(17)$ & $53.6(18)$ \\
Errorless & $38.8(13)$ & $60.0(13)$ & $87.8(6.8)$ & $10.8(7.2)$ \\
$t$ value & $8.12^{\mathrm{c}}$ & & $-10.9^{\mathrm{c}}$ & \\
& & & & \\
Reaction & time (S.D.) & & & \\
Errorful & $867(93)$ & $910(114)$ & $920(122)$ & $897(112)$ \\
Errorless & $859(90)$ & $846(83)$ & $841(73)$ & $940(133)$ \\
& & & & \\
& $d^{\prime}$ & Beta & Precision & \\
\hline Errorful & $0.45(.35)$ & $0.93(.27)$ & $0.57(.07)$ & \\
Errorless & $1.04(.37)$ & $2.89(.33)$ & $0.79(.09)$ & \\
$t$ value & $-8.16^{\mathrm{c}}$ & $-3.57^{\mathrm{b}}$ & $-13.6^{\mathrm{c}}$ & \\
\hline
\end{tabular}

All paired $t$-tests (errorful-errorless) reported had 14 degrees of freedom, ${ }^{\mathrm{a}} P<0.05,{ }^{\mathrm{b}} P<0.001,{ }^{\mathrm{c}} P<0.0001$. 
compared to the EL method. Expectedly, it also led to a greatly increased number of false alarms. While the overall number of detected targets was greater in the EF condition, accuracy, as reflected by the $d$ " and "precision" measures, indicated a better quality of memory performance in the EL condition.

With regard to the response times, it is noteworthy that EF-CR responses were slower than any of the other types of responses. Consequently, in an ANOVA with Condition (EL vs. EF) and Type of response (hits and correct rejections) as factors the interaction of these two factors was significant $(F(1,14)=9.00, P<0.01)$. In addition, a main effect of Condition was found $(F(1,14)=16.1, P<0.001)$ reflecting the overall faster response times in the EL condition (893 vs. $850 \mathrm{~ms}$ ).

\subsection{Stimulus-locked event-related brain potentials (ERPs)}

Fig. 1 shows the grand average ERPs from selected scalp sites for both learning modes. Both, EF-Hits and EF-
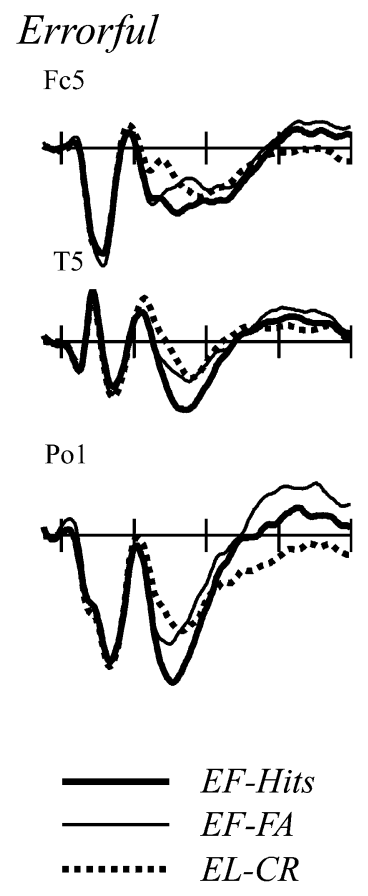

Errorless

Fc5
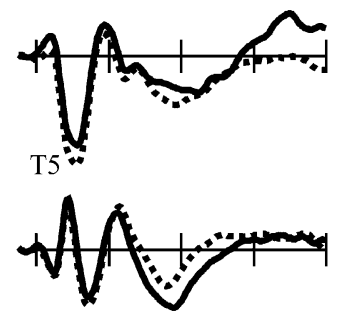

Po1
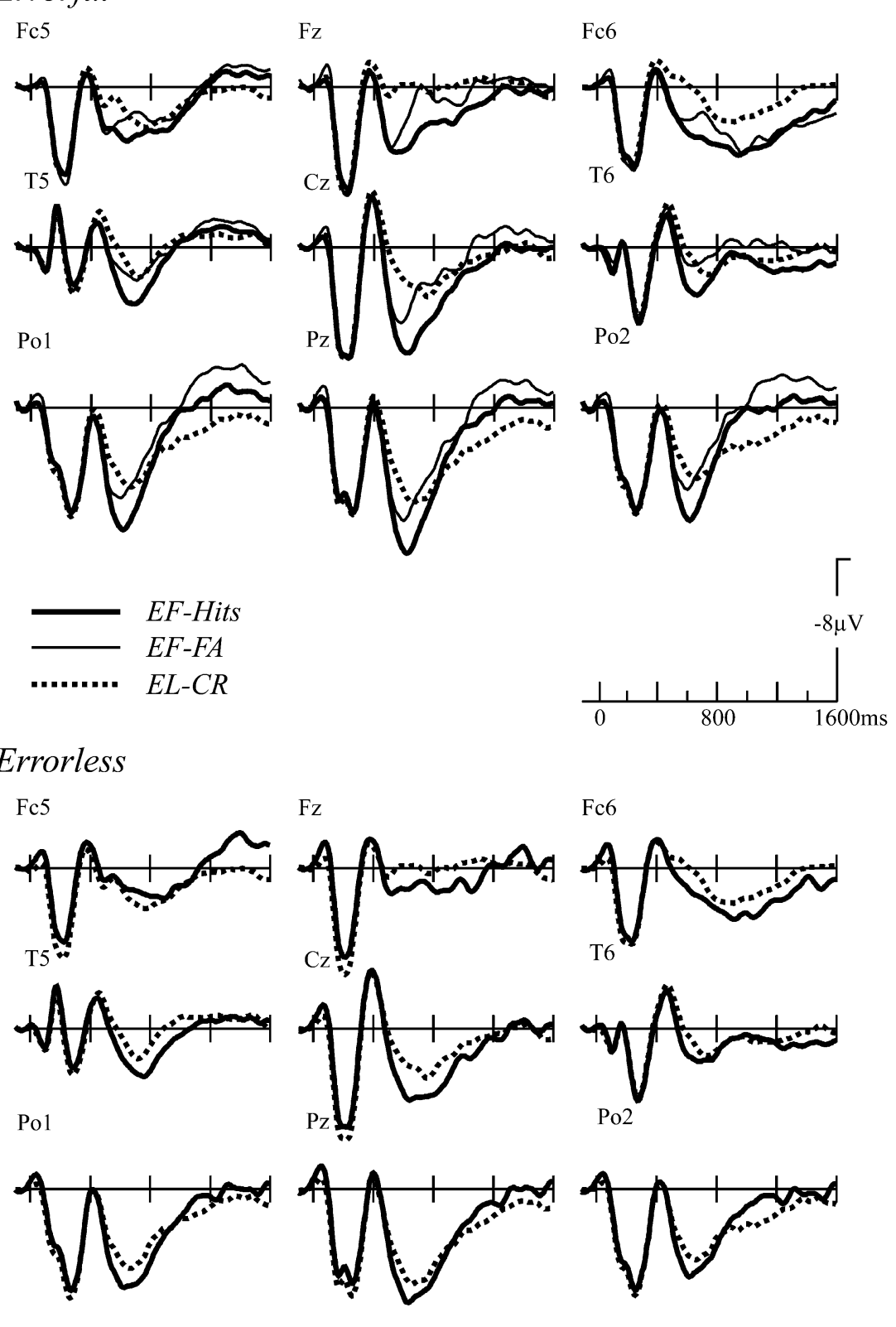

Fz

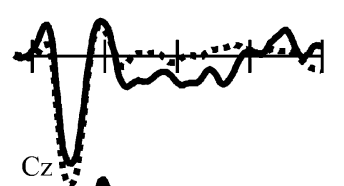

Fc6
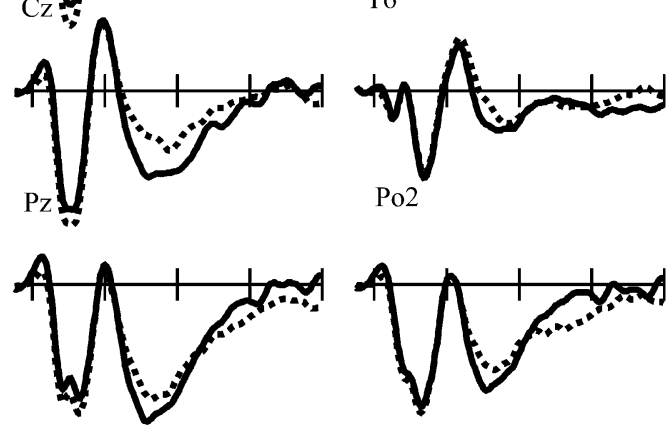

Fig. 1. Grand average ERPs from selected scalp channels. In the top panel hits and false alarms from the EF conditions are compared to EL-CR (correct rejection of new words, i.e. non-target candidate words from the EL condition). Relative to EL-CR both, hits and false alarms, are associated with more positive waveforms. In the lower panel, EL-Hits are compared to EL-CR. Again, a more positive waveform is observed. 
Table 2a

Summary of overall ANOVA applied for the parasagittal, lateral, and midline locations comparing Errorful-hits, Errorful false alarms and EL-CR in different time windows

\begin{tabular}{|c|c|c|c|c|c|c|}
\hline & $D f$ & $\begin{array}{l}300- \\
500 \mathrm{~ms}\end{array}$ & $\begin{array}{l}500- \\
700 \mathrm{~ms}\end{array}$ & $\begin{array}{l}700- \\
900 \mathrm{~ms}\end{array}$ & $\begin{array}{l}900- \\
1200 \mathrm{~ms}\end{array}$ & $\begin{array}{l}1200- \\
1500 \mathrm{~ms}\end{array}$ \\
\hline \multicolumn{7}{|l|}{ Parasagittal } \\
\hline $\begin{array}{l}\text { Type of } \\
\text { stimuli (T) }\end{array}$ & 2,28 & $3.53^{\mathrm{a}}$ & $9.8^{\mathrm{d}}$ & & & \\
\hline $\mathrm{T} \times \mathrm{Hem}$ & 2,28 & & & & & $6.8^{\mathrm{a}}$ \\
\hline $\mathrm{T} \times$ Ant & 12,168 & & & & $5.6^{\mathrm{d}}$ & \\
\hline $\mathrm{T} \times$ Hem $\times$ Ant & 12,168 & & & & $2.74^{\mathrm{a}}$ & $3.0^{\mathrm{a}}$ \\
\hline \multicolumn{7}{|l|}{ Lateral } \\
\hline $\begin{array}{l}\text { Type of } \\
\text { stimuli (T) }\end{array}$ & 2,28 & 5.13 & $13.9^{\mathrm{d}}$ & & $3.6^{\mathrm{a}}$ & \\
\hline $\mathrm{T} \times$ Hem & 2,28 & & & & & $5.5^{\mathrm{a}, \mathrm{nc}}$ \\
\hline $\mathrm{T} \times$ Ant & 8,112 & & & & & \\
\hline $\mathrm{T} \times$ Hem $\times$ Ant & 8,112 & & & & $3.0^{\mathrm{a}, \mathrm{nc}}$ & \\
\hline \multicolumn{7}{|l|}{ Midline } \\
\hline $\begin{array}{l}\text { Type of } \\
\text { stimuli (T) }\end{array}$ & 2,28 & $3.8^{\mathrm{a}}$ & $9.6^{\mathrm{d}}$ & & & \\
\hline $\mathrm{T} \times$ Ant & 4,56 & & & $3.4^{\mathrm{a}}$ & $11.1^{\mathrm{d}}$ & $3.93^{\mathrm{a}}$ \\
\hline
\end{tabular}

Values inside cells correspond to the $F$ values; ${ }^{\mathrm{a}} P<0.05 ;{ }^{\mathrm{b}} P<0.01 ;{ }^{\mathrm{c}} P<0.005$; ${ }^{\mathrm{d}} P<0.001 .{ }^{\mathrm{nc}}$ The corresponding interaction tested which includes electrode sites did not show a significant value after vector normalization $(P>0.05 ; F$ values reported correspond to the non-normalized data). Blank cells in the table were not significant $(P>0.05)$. Main effects of hemisphere (Hem) and anterior-posterior location (Ant) have been left out for sake of brevity.

FA items, were associated with a more positive waveform relative to EL-CR starting at about $400 \mathrm{~ms}$ and peaking at about $600 \mathrm{~ms}$. While this old/new effect is clearly present in the EF-FA items, i.e. those items that had been "incorrectly" guessed during EF learning, it was considerably larger in the EF-Hits stimuli. It is noteworthy, that the early portion of the old/new effect in EF-Hits and EFFA was virtually identical and that the two waveforms started to diverge at approximately $500 \mathrm{~ms}$. These waveforms were compared by a set of ANOVAs carried out on mean amplitude measures in different successive timewindows summarized in Table 2a. These ANOVAs were followed up by pairwise comparisons. The pairwise comparison EF-Hits/EL-CR was significant for between 300 and $700 \mathrm{~ms}$ (all $d f(1,14)^{1}: 300-500 \mathrm{~ms}: F=6.62, P<0.05$; 500-700 ms: $F=8.7, P<0.001 ; 700-900 \mathrm{~ms}: F=3.29$, $P>0.1 ; 900-1200$ ms: $F=0.28$, n.s.; $1200-1500$ ms: $F=0.41$, n.s.). A similar pattern was observed for the comparison EF-FA/EL-CR $(300-500 \mathrm{~ms}: F=11.8$, $P<0.01$; 500-700 ms: $F=4.7, P<0.05$; 700-900 ms: $F=0.29$, n.s.; $900-1200$ ms: $F=0.99$, n.s.; $1200-1500$ ms: $F=2.13$, n.s.), while EF-Hits/EF-FA yielded a significant effect only in the 600-800 ms time-window $(F=5.92, P<0.03)$. The lower part of Fig. 1 compares

\footnotetext{
1 For the sake of brevity, only the pairwise comparisons for the midline electrodes are shown here. Similar results were obtained for the parasagittal electrodes.
}

Table $2 b$

Errorless-hits against EL-CR (errorless correct rejections)

\begin{tabular}{llllll}
\hline$d f$ & $300-$ & $500-$ & $700-$ & $900-$ & $1200-$ \\
& $500 \mathrm{~ms}$ & $700 \mathrm{~ms}$ & $900 \mathrm{~ms}$ & $1200 \mathrm{~ms}$ & $1500 \mathrm{~ms}$
\end{tabular}

\section{Parasagittal}

Type of stimuli (T) 1,14

$\mathrm{T} \times$ Hem $\quad 1,14$

$\mathrm{T} \times$ Ant $\quad 6,84$

$\mathrm{T} \times$ Hem $\times$ Ant $\quad 6,84$

14
6,84

$\begin{array}{lll} & & 5.4^{\mathrm{a}} \\ 4.9^{\mathrm{b}} \quad 4.1^{\mathrm{a}} \quad 3.6^{\mathrm{a}} \quad 4.7^{\mathrm{a}}\end{array}$

Lateral

Type of stimuli (T) 1,14

\begin{tabular}{|c|c|c|c|}
\hline pe & 1,14 & & \\
\hline $\mathrm{T} \times$ Hem & $1,14 \quad 5.5^{\mathrm{a}}$ & $5.2^{\mathrm{a}}$ & $7.1^{\mathrm{a}}$ \\
\hline $\mathrm{T} \times$ Ant & 4,56 & & \\
\hline $\mathrm{T} \times \mathrm{Hem} \times \mathrm{Ant}$ & 4,56 & $3.2^{\mathrm{a}}$ & \\
\hline
\end{tabular}

Midline

Type of stimuli (T) 1,14

$\mathrm{T} \times$ Ant $\quad 2,28$

Values inside cells correspond to the $F$ values; ${ }^{\mathrm{a}} P<0.05 ;{ }^{\mathrm{b}} P<0.01$; ${ }^{\mathrm{c}} P<0.005 ;{ }^{\mathrm{d}} P<0.001$. ${ }^{\mathrm{nc}}$ The corresponding interaction tested which includes electrode sites did not show a significant value after vector normalization $(P>0.05 ; F$ values reported correspond to the nonnormalized data). Blank cells in the table were not significant $(P>0.05)$. Main effects of hemisphere (Hem) and anterior-posterior location (Ant) have been left out for sake of brevity.

EL-Hits and EL-CR. Visual inspection suggests the presence of a typical old/new effect. This effect was captured statistically by significant interaction effects (Type by hemisphere by anterior/posterior) as shown in Table $2 \mathrm{~b}$.

EF-Hits were significantly more positive than that to ELHits (see Fig. 2A) indicating a more pronounced old/new

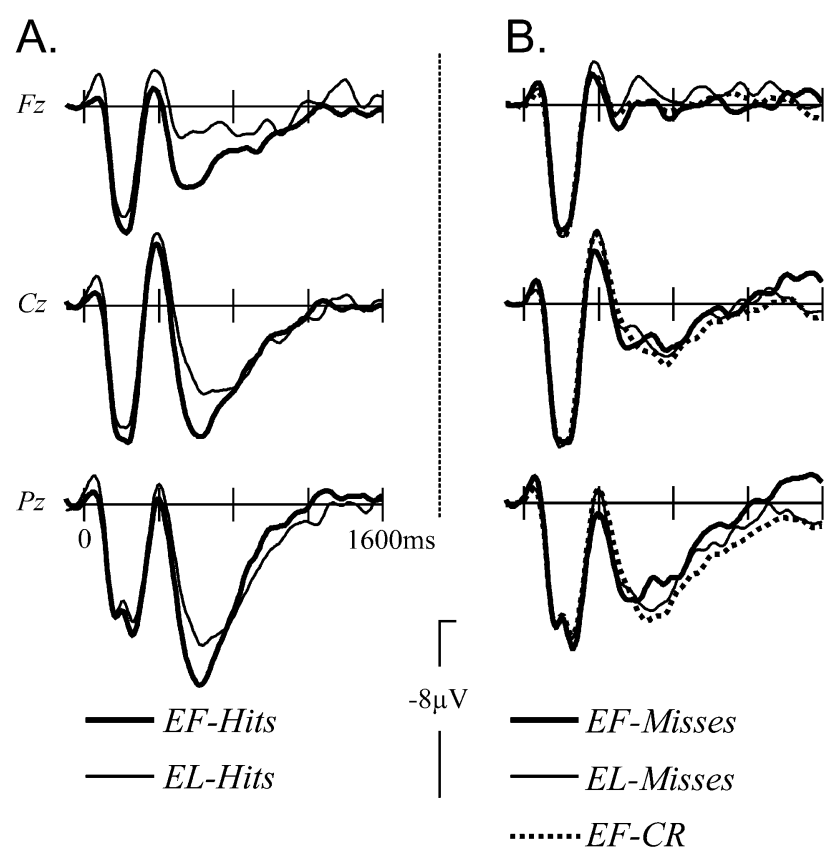

Fig. 2. (A) A direct comparison of ERPs to hits for both learning methods. The increased LPC component in the EF condition reflects the deeper encoding of target words guessed during the study phase. (B) Miss trials from both learning conditions are compared to EL-CR trials. 
Difference

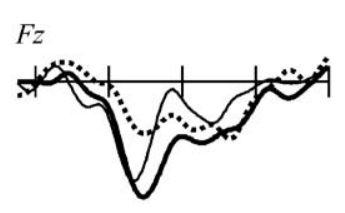

$C z$
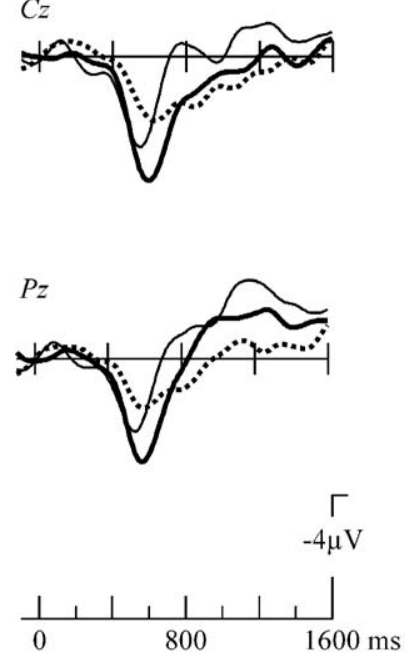

Early
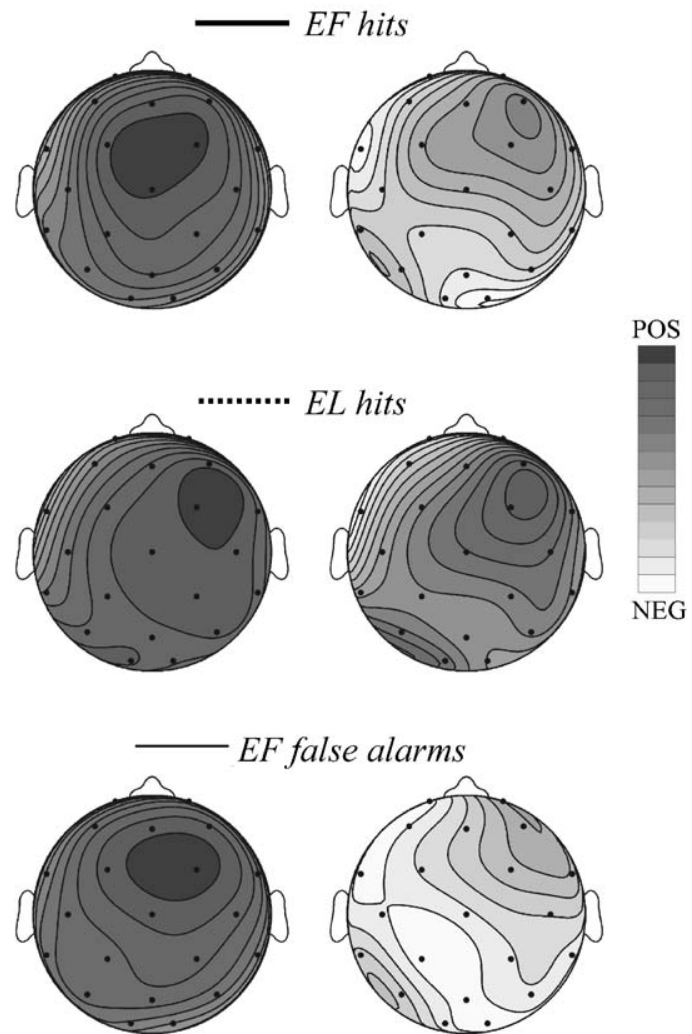

Fig. 3. Difference waveforms computed by subtracting the ERPs of EF-Hits, EF-FA and EL-Hits from the baseline condition EL-CR. Notice the reduction of amplitude and later onset of the positivity for EL-Hits compared to both EF categories. The spline interpolated isovoltage maps depict the mean amplitude in the time-windows 555-595 ms (early) and 715-735 ms (late).

effect in this condition (all $d f(1,14)$; midline, 300-500 ms: $F=8.23, P<0.05 ; 500-700$ ms: $F=9.92, P<0.01 ; 700-$ 900 ms: $F=0.34$, n.s., $900-1200$ ms: $F=0.03$, n.s.; $1200-$ $1500 \mathrm{~ms}: F=0.01$, n.s; parasagittal, $300-500 \mathrm{~ms}: F=13.6$, $P<0.001$; 500-700 ms: $F=23.1, P<0.0003$; 700-900 ms: $F=1.25$, n.s.; $900-1200 \mathrm{~ms}: F=0.01$, n.s.; $1200-1500 \mathrm{~ms}$ : $F=0.02$, n.s.; temporal, $300-500 \mathrm{~ms}: F=9.83, P<0.01$; 500-700 ms: $F=32.2, P<0.001 ; 700-900 \mathrm{~ms}: F=6.46$, $P<0.05$; $900-1200 \mathrm{~ms}: \mathrm{F} 7.66, P<0.02 ; 1200-1500 \mathrm{~ms}$ : $F=5.6, P<0.05)$.

By contrast no significant differences were noticeable between the ERPs to the EF-Misses and EL-Misses (Fig. 2B; midline, parasagittal, temporal electrode sets, for all time-windows between 300 and $1500 \mathrm{~ms}$, all $F(1,14)$ $<1.6$, all n.s.). To further illustrate the old/new effect, difference waves were computed by subtracting the EFHits, EL-Hits, and EF-FA ERPs from the new word (EL$\mathrm{CR}$ ) baseline condition. These are illustrated in Fig. 3 together with topographical isovoltage maps. The old/new effect occurred somewhat earlier in the EF-FA and EFHits condition compared to the EL-Hits condition. Moreover, while a frontal maximum was found in the earlier time-window for all three difference waves, the distribution in the EL-Hits condition showed a clear right preponderance. These topographical differences were fol-
Errorful
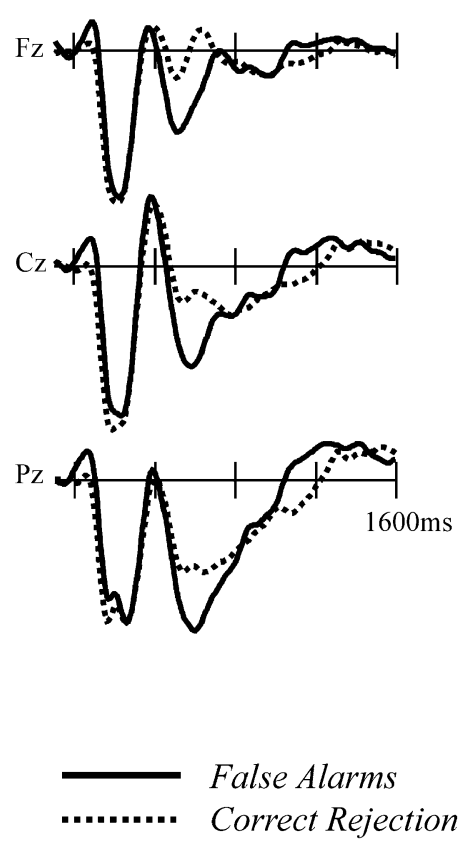

Fig. 4. Comparison of ERPs to false alarms (non-target words classified as targets) and correct rejections (non-target words classified as non-targets) for both learning methods. 


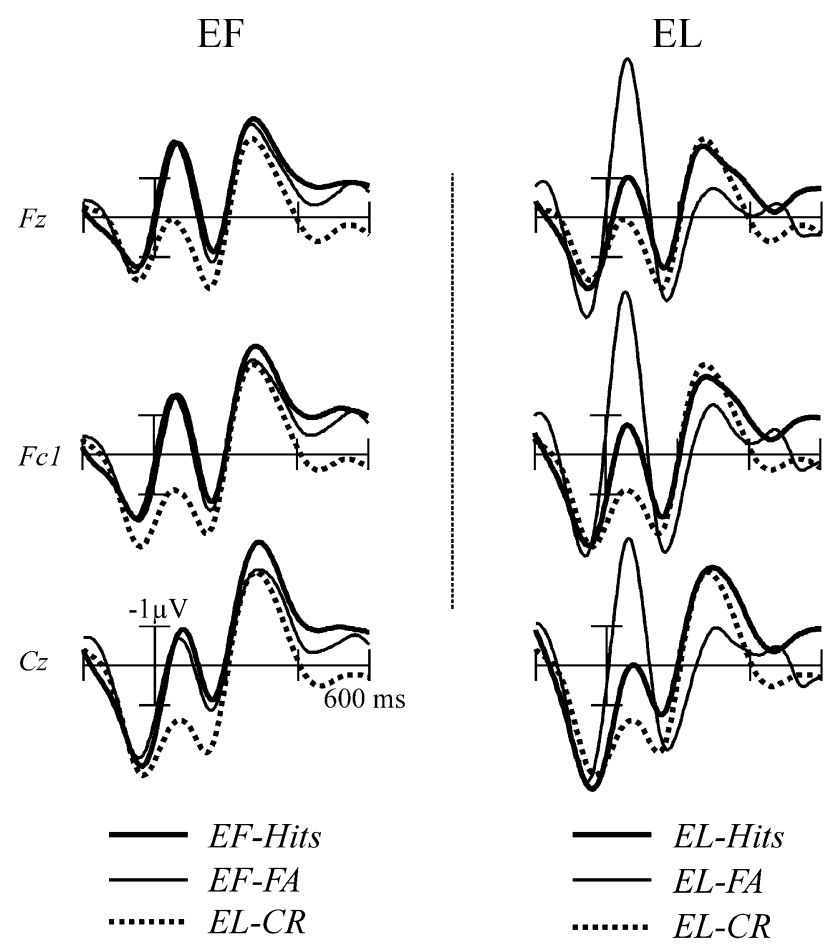

Fig. 5. Response-locked averages showing hits and false alarms in both learning conditions. The baseline condition EL-CR is shown for comparison. Notice the increased amplitude of hits (correctly recognized words) and false alarms (erroneous trials) compared to the baseline condition. ERPs shown were adjusted according to the mean amplitude in the -300 to $-50 \mathrm{~ms}$ interval. Note that this baseline is not shown completely.

lowed up by computing an ANOVA with condition (EFHits, EF-FA, EL-Hits) and electrode (29 positions) as factors. The ANOVA was performed after application of the vector-normalization procedure [40]. The interaction between condition and electrode was significant (all $d f(56,789) ; 500-600 \mathrm{~ms} \quad F=2.22, \quad P<0.05) ; 600-700$ ms: $F=1.90, P<0.05 ; 700-800 \mathrm{~ms}: F=2.43, P<0.01)$ suggesting that indeed the distributions of the three difference waves are different.

Fig. 4 illustrates the comparison between false alarms and correct rejections for both learning conditions. The EF-FA items were associated with a more positive waveform with an onset around $400 \mathrm{~ms}$, which was significant in the 300-500 ms time-window (midline, $F=10.22$, $P<0.01$; parasagittal, $F=11.24, P<0.01)$. This pattern is not present in the EL condition (all $F<1.1$ ).

\subsection{Response-locked ERPs}

In order to better delineate the response-related negative components, response-locked averages were high-pass filtered ( $1 \mathrm{~Hz}$ half amplitude cut-off). Such a filter has been used previously in studies on the error-related negativity [54] and attenuates the amplitude of the late positive component overlapping the response-related neg- ativity. The mean amplitude in the time-window between -300 and $-50 \mathrm{~ms}$ before the response was used to realign the response-locked ERPs. Figs. 5 and 6 illustrate the response-locked waveforms. The corresponding topographical distributions can be derived from Fig. 7. Two different negative peaks are clearly visible in these waveforms. The first component shows a peak at about $70 \mathrm{~ms}$ and is maximal at frontocentral locations. It thus resembles the topographical distribution of the error-related negativity (ERN). The second negative component has a peak around $320 \mathrm{~ms}$ and a clearly different topographical distribution with a maximum at parietal sites. Note that these two components are also visible, albeit "smeared out in time", in some of the stimulus-locked averages (Figs. 1, 2, and 4).

Because of the midline maximum of the response-locked ERPs, statistical analyses were restricted to midline locations. ANOVA-results can be derived from Table 3. These were followed up by pairwise comparisons as specified in the following paragraphs (all $d f(1,14)$ ).

In the EF condition, both EF-Hits and EF-FA are associated with an ERN, which is not present in the EL-CR trials (Fig. 5, left column). The first negative peak was assessed by a mean amplitude measure (interval between 0 and $100 \mathrm{~ms}$ ) at midline locations (Fz, Cz, $\mathrm{Pz}$ ). This showed a significant difference between EF-Hits and EL-CR $(F=9.04, P<0.01)$ and EF-FA and EL-CR $(F=6.22, P<0.03)$. No differences were found between EF-Hits and EF-FA $(F<1)$. In the EL condition, EL-Hits were associated with an ERN-like negativity, which approached statistical significance $(F=0.01, P=0.1$, compared against EL-CR). EL-FA trials clearly showed the highest amplitude of the ERN-like component and statistical comparison was significant when compared to ELCR $(F=16.28, P<0.005)$ as well as to EL-Hits $(F=9.90, P<0.01)$.

In Fig. 6, correct rejections (i.e. correct trials) are compared to false alarms (i.e. error trials) for both learning conditions. In both conditions, correct rejections were associated with a much smaller amplitude of the negative component compared to false alarms. In an

Table 3

Response-locked ERPs, statistical effects

\begin{tabular}{lllll}
\hline & $d f$ & $50-100 \mathrm{~ms}$ & $100-200 \mathrm{~ms}$ & $200-300 \mathrm{~ms}$ \\
\hline Midline locations & & & \\
Learning mode (L) & 1,14 & & \\
Type of stimuli (T) & 2,28 & $12.9^{\mathrm{d}}$ & $3.4^{\mathrm{a}}$ & \\
$\mathrm{L} \times \mathrm{T}$ & 2,28 & $6.43^{\mathrm{c}}$ & & $9.6^{\mathrm{d}}$ \\
$\mathrm{L} \times$ Ant & 2,28 & & \\
$\mathrm{~T} \times$ Ant & 4,56 & & \\
$\mathrm{~L} \times \mathrm{T} \times$ Ant & 4,56 & & \\
\hline
\end{tabular}

Values inside cells correspond to the $F$ values, ${ }^{\mathrm{a}} P<0.05 ;{ }^{\mathrm{b}} P<0.01$; ${ }^{\mathrm{c}} P<0.005 ;{ }^{\mathrm{d}} P<0.001$. Blank cells in the table were not significant $(P>0.05)$. Learning mode (Errorless vs. Errorful); Type of stimuli (Hits, Correct Rejections, False alarms); Ant/Posterior (Fz, Cz, Pz). 


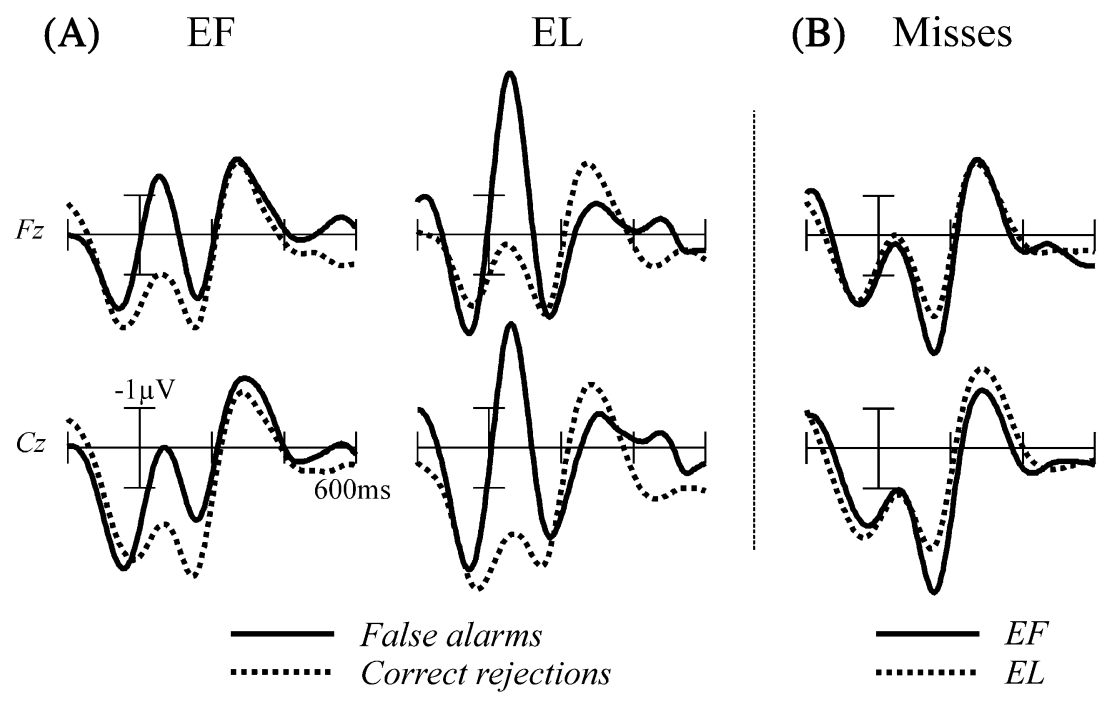

Fig. 6. (A) Response-locked averages comparing correct rejections vs. false alarms in both EF and EL conditions. An increased negativity for the false alarms (error trials) compared to the correct rejections is present in particular in the EL condition. (B) Miss-trials from both learning conditions. ERPs shown were adjusted according to the mean amplitude in the -300 to $-50 \mathrm{~ms}$ interval. Note that this baseline is not shown completely.

ANOVA with Learning mode and Type of response (CR and FA) as within subject factors (midline electrodes, $0-$ $100 \mathrm{~ms}$ ), no main effect of Learning mode was obtained $(F=3.38, P>0.08)$. The larger ERN in false alarm trials was reflected by a main effect of Type of response $(F=19.65, P<0.001)$. The interaction between Learning and Type of trial was not significant $(F(1,14)=2.77$, $P>0.12)^{2}$

The second negative peak was quantified by a mean amplitude measure (200-300 ms, midline locations). An ANOVA (see Table 3) revealed no main effects of Learning mode and Type of trial but a significant interaction effect. This interaction reflects the decreased amplitude of the second negativity for EL-FA trials relative to the other conditions.

\section{Discussion}

The present investigation is aimed at the delineation of brain responses that might index the activity of an error checking system in episodic retrieval as suggested by several authors $[6,42,46,62,64]$. To this end we investigated ERPs elicited by items learned under errorful or errorless conditions. Clear behavioral and electrophysiological differences emerged between both conditions. The most important result of the present study is that a negative component akin the ERN was obtained in the response-locked averages which appears to index the activity of the error checking system, as we will argue below. First, however, we would like to discuss the

\footnotetext{
2 In a further ANOVA analysis with Learning mode and Response type (CR vs. Miss), no main or interaction effects were obtained.
}

behavioral effects and the stimulus-locked ERPs. Behaviorally, the manipulation of errorful vs. errorless encoding had profound consequences. The accuracy and precision of memory performance, as indexed by $d^{\prime}$ and precision measures of signal detection theory, was considerably improved for items that had been acquired under errorless conditions. Thus, the experimental manipulation, in principle, has been successful. The overall number of detected targets was greater under errorful conditions, however, and this condition was also associated with a greatly enhanced rate of false alarms. This difference in the number of hits between the two conditions suggests that items in the errorful conditions were encoded more deeply and that a level of processing manipulation (cf. Ref. [11]) might have been introduced. Indeed, the time needed for guessing the correct word during EF was considerably longer than the time taken to present a word during EL. This interpretation is also supported by the results for the stimulus-locked brain potentials. ERPs to EF-Hits were more positive than those to EL-Hits (Fig. 2A). In previous studies explicitly manipulating the level of processing at encoding, the LPC but not the N400 portion of the old/ new effect was enhanced for deeply encoded items [47,48,57]. A second ERP-result of interest concerns the false alarm trials from the EF-condition. This category comprised words that had been produced by the subject during the learning phase but had been labelled as "incorrect" by the experimenter. These words were associated with an increased positivity between 400 and 700 ms compared to EL-CR. Interestingly, EF-Hits and EF-FA began to differ after $600 \mathrm{~ms}$. Thus, EF-FA were characterized by an old/new effect but the amplitude of this effect was significantly reduced relative to EF-Hits between 600 and $800 \mathrm{~ms}$. A similar effect is absent for the EL condition in which false alarms pertained to words 
that had not been encountered during encoding. Thus, the pattern in the EL-condition is similar to other studies that did not report old/new effects for false alarms (e.g. $[67,79]$. In other words, the old/new effect for EF-FA appears to be related to the specific learning method used. With regard to the distribution of the old/new effects in the present study (Fig. 3), it is noteworthy that all three conditions (EF-Hits, EF-FA, EL-Hits) showed a frontal maximum. Only the distribution of the EL-Hits condition, however, showed a right frontal maximum, while the other two had a more bilateral condition. Together with the earlier onset latency of the old/new effect in EF-Hits and EF-FA, this suggests that a significant contribution to the effect in these conditions come from the modulation of the N400 component (cf. Ref. [41]), implying familiarity based recognition. Note that right-frontal effects similar to the one seen in the EL-Hits condition have been reported in a number of recent experiments. For example, Wilding and Rugg [77] described a right-frontal component in a source retrieval paradigm. In this type of task, subjects are required to make a double decision, i.e. an old/new judgment followed by a decision requiring access to the specific learning episode (source judgment). Wilding and Rugg [77] proposed that this component reflected "post-retrieval operations" on the retrieval products (see also Ref. [14]). Düzel et al. [16] reported a similar effect in an experiment using the remember/know paradigm. While no final conclusion about the nature of this effect has been reached, it appears to be clear that it is associated to the evaluation of the quality of the retrieved memory trace. In fact, the present task taxed the monitoring device to a greater extent than standard old/new tasks, as the subject not only had to decide for each word whether it was "old" but also whether or not it had been a "target" during encoding. Thus, a situation similar to the source memory paradigm is created. Interestingly, recent neuroimaging studies showed differential activity of right prefrontal cortex in episodic memory retrieval processes (see for a review Refs. [21,59]). Some of them have proposed that the right dorsolateral and anterior prefrontal cortex supports monitoring operations during episodic retrieval tasks $[1,26,27,28,65]$. Likewise, an fMRI study by Herrmann et al. [29] revealed right prefrontal activations for words that had been intensively studied but were then marked as non-targets and had to be rejected during retrieval. The involvement of right frontal cortex in the monitoring and evaluation of errors during retrieval is also suggested by neuropsychological studies showing that repetition errors in free recall tend to occur in patients with right dorsolateral frontal damage [71].

Most important with regard to the proposed error-checking mechanism during memory retrieval $[6,42,43,46,62,64]$ are the response-locked averages. Morphology, peak latency and distribution (see Fig. 7) of the negative component occurring after the response are identical to that of the
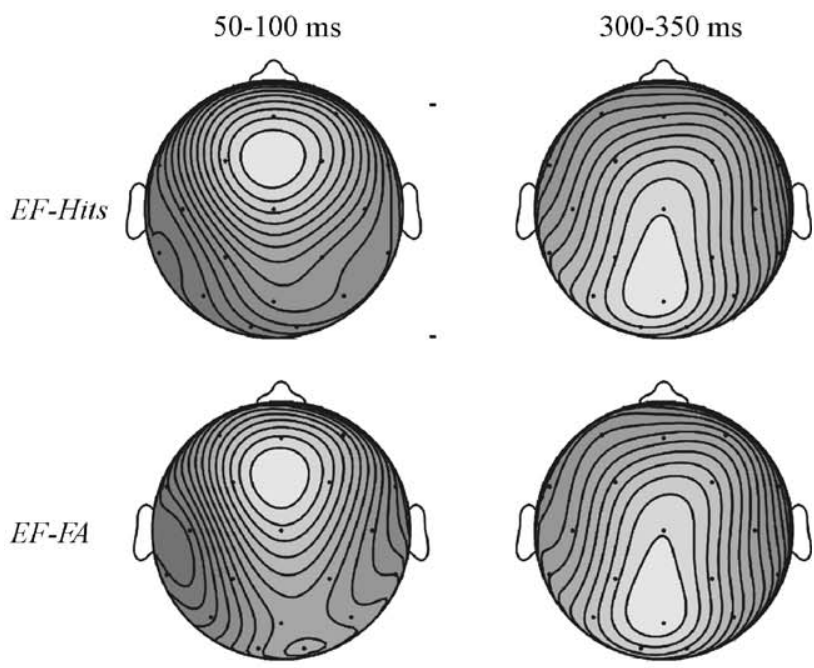

EL-Hits
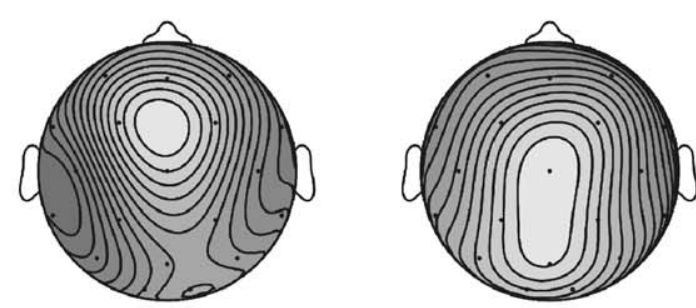

$E L-F A$
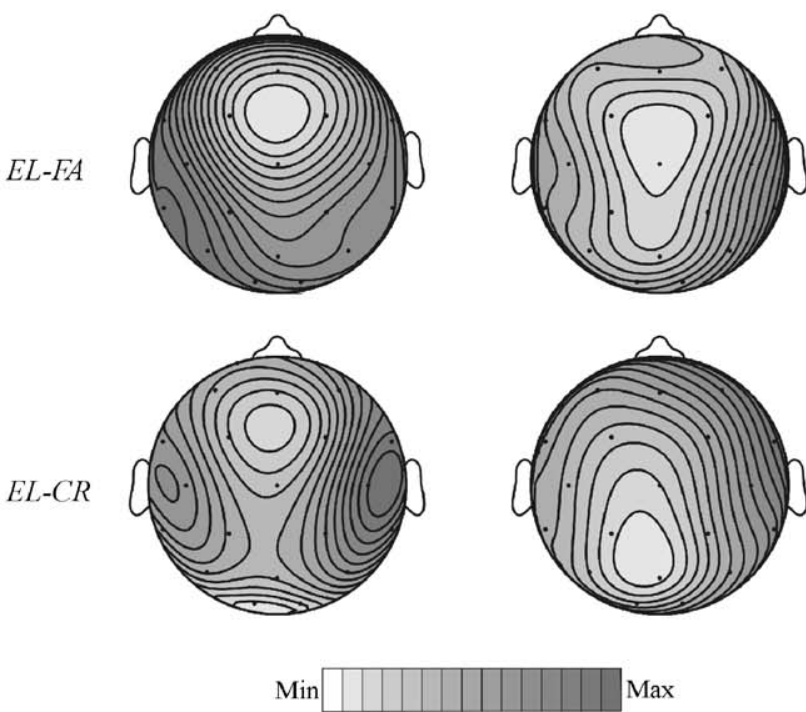

Fig. 7. Response-locked spline interpolated isovoltage maps. In the 50-100 ms time window, the typical frontocentral midline distribution of the errorrelated negativity is observed, while in the $300-350 \mathrm{~ms}$ interval, a more posterior distribution is seen. Note that relative scaling was used (maximum and minimum values in $\mu \mathrm{V}$ for each map from top to bottom at $50-100$ $\mathrm{ms}:-1.5 \mathrm{~V} /-5.7,-0.3 /-2.9,0.03 /-3.0,-1.5 /-5.7,-0.8 /-1.4$; at $300-350 \mathrm{~ms}:-0.5 /-5.2,-0.7 /-4.4,-0.6 /-5.0,-0.05 /-3.1$, $-0.3 /-4.8)$

error-related negativity, a component that has been originally described following erroneous responses [19,22,23]. In subsequent studies it has also been found for correct responses under certain circumstances $[10,38,61,75]$. Clear and unequivocal ERNs of varying size are present EF-Hits, EF-FA, EL-Hits and EL-FA, while the ERN is small to 
absent in the CR and Miss trials from both conditions. This pattern of results can be explained with regard to the response conflict model of the ERN [5,7]. This model holds that the degree to which a "conflict monitor" is activated depends on the product of the current activations for each of two concurrently available response alternatives: Thus, if the retrieval process indicates that the subject has encountered a particular stimulus before, as in the Hit and FA trials, it has to be checked whether this item is indeed correct or not. Note that in the current experiment for items coming from the errorful learning process, two responses (target or non-target) are likely to be activated to a similar degree, whenever an item seemed familiar. In this case, the response conflict model would predict a sizeable ERN, which was indeed the case in the actual data. Trials from the EL- and EF-learning modes occurred intermixed during the study phase. This should lead to a great activation of the target-response but at the same time to some rudimentary activation of the non-target response in the EL-Hit trials, thus resulting in an ERN. The fact that the EL-FA trials are associated with the largest ERN component might appear somewhat puzzling. Recall, however, that the EL-FA trials concerned items that were not encountered during the study phase and therefore should give rise to a greater activation of the "no-target" response that would compete with the actual "target"-response given by the subject.

Can the response conflict model also explain the ERNresults for the "no"-responses? Here, regardless of whether or not the subject was right (CR) or not (Miss), very small or absent ERNs were obtained. This is somewhat puzzling, because in the EF-CR, EF-Miss and EL-Miss trials the subjects had encountered the particular item during the study phases. However, if one considers that the error checking mechanism might only come into play, if the output of the retrieval process exceeds a certain threshold, the pattern of results can be explained. In other words, if the retrieval process does not yield a result, this appears to lead to unambiguous activation of the "no"-response and no ERN is emitted. The current study is only the second instance of a report of an ERN-(like)-component in a memory task. Recently, Nessler and Mecklinger [44] have reported a similar effect, which, in contrast to the current study, was more posteriorly distributed however. These authors speculated that the difference to the classical fronto-central distribution of the ERN found in perceptual tasks might be due to the fact that different portions of the anterior cingulate cortex might have been recruited in their task, possibly related to more evaluative processes. At this point we are unable to pinpoint the exact factors that might be responsible for the topographical differences between the current and the Nessler and Mecklinger study. Interestingly, a second negative peak following the ERN was observed in the current study. The scalp maximum of this second peak is centroparietal and clearly different from that of the ERN. While a selective amplitude reduction of this peak was found for EL-FA trials, determination of its functional significance must await further studies.

To conclude, the current study demonstrates that stimulus-locked and response-locked ERPs can be used to distinguish different monitoring stages implied in episodic memory retrieval. Combined with other neuroimaging techniques, future studies will need to address the contribution of different frontal areas in monitoring, evaluating, and verifying recovered memory traces in accordance to the goals of the memory task.

\section{Acknowledgements}

We thank A. Richardson-Klavehn and E. Düzel for generously sharing their stem-completion data. ARF received support from the Spanish government. Also supported by grants from the DFG and BMBF to TFM.

\section{Appendix A. Word candidates used in the stem completion task (selected from unpublished data of Richardson-Klavehn and Düzel)}

LIST A. Ableitung Ablage/Oper Operation/Artikel Artist/Bach Backen/Becher Becken/Bonbon Bonus/Billig Bild/ Bier Biene/Bügel Bügeln/Daumen Dauer/Brötchen Brösel/ Bote Botschaft/Chemie Chef/Doktor Dokument/Dick Dicht/ Durst Durch/Eigen Eignung/Ehre Ehrlich/Elite Elipse/Erhaben Erhalten/Dusche Dussel/Epoche Epos/Ernte Ernst/Experiment Experte/Fahren Fahne/Feuer Feudal/Fistel Fisch/ Frage Frau/Fuss Fussel/Fibel Fiber/Fördern Förster/Gabel Gabe/Frust Frucht/Gitter Gitarre/Gondel Gong/Hager Hagel/Giebel Giessen/Gosse Gospel/Grübeln Grün/Hammer Hammel/Hecht Hecke/Hobel Hobby/Hose Hospital/Hülle Hülse/Hitze Hitliste/Honig Honorar/Hund Hunger/Inzucht Inzest/Jubel Jubiläum/Kahn kahl/Kader Kadaver/Kappe Kapsel/Kiefer Kies/Kammer Kamm/Kessel Kess/Kissen Kiste/Knochen Knoten/Kippe Kippen/Korb Korken/Kauen Kaufen/Kirsche Kirche/Klug Klumpen/Kultur Kuli/Land Lanze/Kuchen Kuckuck/Labor Laben/Latte Laterne/Kosmos Kosten/Kuss Kuscheln/Lamm Lampe/Loge Logisch/ Linse Links/Loch Locke/Leder Ledig/Liebe Liege/Lokomotive Lokführer/Matte Matt/Melken Meldung/Mimik Mimose/Mollig Molke/Most Moslem/Mode Modern/Motte Motor/Messer Messe/Mobil Mobbing/Morgen Mord/Mund Munter/Mütter Mütze/Nippel Nippen/Nebel Neben/Nest Nessel/Murren Murmel/Nach Nackt/Obdach Obdachlos/Patient Patent/Original Orient/Pochen Pocken/Punsch Punkt/ Rache Rachen/Requiem Requisit/Regen Regel/Orakel Orange/Rock Rochen/Ruck Rucksack/Sack Sache/Rubin Rubrik/Rute Rutsche/Robbe Robe/Sediment Sedieren/Skat Skandal/Sand Sanieren/Semmel Seminar/Saal Saat/Salz Salbe/Soft Sofort/Skelett Sketch/Segen Segel/Sinn Singen/ Soda Sodbrennen/Telefon Teller/Takt Taktik/Suite Suizid/ Tapete Tapfer/Tennis Tenne/Umgang Umgebung/Vene Ven- 
til/Uran Uralt/Vital Vitamine/Wahn Wahnsinn/Wade Wadi/ wucht wucher/Zauber Zaun/Wedeln weder/Zisterne Zischen/Würgen Würfel/Zeche Zecke/Zwang zwar/Zirkel Zirkus/Zunge Zunder/Panne Panzer/Pedal Pedant/Vetter Veteran/Pyramide Pyromane/Zappeln Zapfen/Pfund Pfusch/Vehikel Vehement/Witz Witwe/Poker Pokal/Turnen Turm/Surfen Surren.

LIST B. Abnehmen Abnahme/Abzeichen Abzug/Atlas Atlantik/Anzeige Anzahl/Bahn Bahre/Bohne Bohrer/Bibel Biber/Birke Birne/Blase Blasen/Bündel Bündnis/Defekt Definition/Burg Bursche/Bürger Büro/Deutsch Deuten/ Denken Denn/Drachen Drache/Dutt Dutzend/Edel Eden/ Eiter Eitel/English Enge/Dünn Düne/Echt Echo/Erker Erkennen/Etage Etat/Fach Fackel/Faul Faust/Firma First/ Flöte Flöhe/Fröhlich Frösche/Galle Galgen/Filter Film/ Frisch Frist/Globus Glocke/Gatte Gatter/Glück Glühwein/ Gurke Gurt/Heft Hefe/Girlande Giraffe/Greifen Greis/Hafen Hafer/Heben Hebamme/Hirse Hirsch/Hopfen Hopsen/Hufe Hufeisen/Henne Henkel/Hoheit Hohn/Hummer Hummel/ Hütte Hüte/Ingenieur Ingwer/Kachel Kacke/Kaktus Kakerlake/Kaiser Kaimauer/Kegel kegeln/Jauche Jauchzen/Keim Keil/Kichern Kicken/Knabe Knast/Kopf Koppel/Knebel Knete/Krebs Kreide/Kehle Kehren/Klage Klammer/Krone Krokodil/Kupfer Kuppel/Kruste Krug/Kummer Kumpel/ Lage Lager/Orchester Orchidee/Kunde Kunst/Lachen Lack/Liste List/Netz Nett/Literatur Liter/Laufen Laut/Lesen lesbisch/Lodern Loden/Lunge Lunte/Meckern Mechanik/ Miete Mieder/Mohn Mohr/Moor Moos/Miktion Mikado/ Moped Mops/Münze Münster/Mögen Möglich/Mond Montag/Mühe Mühle/Mürbe Mürrisch/Nase Nass/Nagel Nager/ Neid Nein/Niete Niemand/Mutter Mutig/Narbe Narr/Ober Oben/Person Perle/Pfote Pforte./Podest Podium/Putzen Pute/Rampe Rammen/Reue Reuse/Rennen Rente/Religion Relief/Route Rouge/Rüssel Rüstig/Rodeln Roden/Ruhe Ruhm/Riese Riemen/Rose Rost/Silbe Silber/Saft Safari/Sattel Satt/Russisch Russ/Sahne Sahara/Smart Smaragd/Sieb Sieben/Sohle Sohn/Sekunde Sekt/Sitzen Sitte/Sorge Sorte/ Tief Tier/Tempel Tempo/Tagung Tage/Thymian Thymus/ Ticken Tick/Tüll Tülle/Umsatz Umstand/Vieh Viel/Vokal Vokabel/Volumen Voll/Wolke Wolle/Zange Zanken/Watte Watt/Wurzel wurm/Zittern Zitat/Zahn Zahl/Zusammen Zusatz/Zimmer Zimt/Zucker Zucht/Zeit Zeitung/Thema These/Wecker Wechsel/Tanne Tanzen/Pause Pauken/Quote Quotient/Pille Pilz/Pavian Pavillon/Prüfung Prügel/Piste Pissen/Teig Teich.

\section{References}

[1] K. Allan, R.J. Dolan, P.C. Fletcher, M.D. Rugg, The role of the right anterior prefrontal cortex in episodic retrieval, NeuroImage 11 (2000) 217-227.

[2] R.H. Baayen, R. Piepenbrock, H. Van Rijn, The CELEX lexical database, Linguistic Data Consortium, University of Pennsylvania, Philadelphia, 1993.

[3] A. Baddeley, B.A. Wilson, When implicit learning fails: amnesia and the problem of error elimination, Neuropsychologia 32 (1994) 53-68.

[4] D.M. Barch, T.S. Braver, F.W. Sabb, D.C. Noll, Anterior cingulate and the monitoring of response conflict: evidence from an fMRI study of Overt Verb Generation, J. Cogn. Neurosci. 12 (2000) 298-309.

[5] M.M. Botvinick, T.S. Braver, D.M. Barch, C.S. Carter, J.D. Cohen, Conflict monitoring and cognitive control, Psychol. Rev. 108 (2001) $562-624$

[6] P.W. Burgess, T. Shallice, Confabulation and the control of recollection, Memory 4 (1996) 359-411.

[7] C.S. Carter, T.S. Braver, D.M. Barch, M.M. Botvinick, D. Noll, J.D. Cohen, Anterior cingulate cortex, error detection, and the on-line monitoring performance, Science 280 (1998) 747-749.

[8] C.S. Carter, A.M. Macdonald, M.M. Botvinick, L.L. Ross, V.A. Noll, D. Noll, J.D. Cohen, Parsing executive processes: strategic vs. evaluative functions of the anterior cingulate cortex, Proc. Natl. Acad. Sci. 97 (2000) 1944-1948.

[9] J.D. Cohen, M. Botvinick, C.S. Carter, Anterior cingulate and prefrontal cortex: who's in control, Nat. Neurosci. 3 (2000) 421-423.

[10] M.G.H. Coles, M.K. Scheffers, C.B. Holroyd, Why is there an ERN/ $\mathrm{Ne}$ on correct trials? Response representations, stimulus-related components, and the theory of error-processing, Biol. Psychol. 56 (2001) $173-189$.

[11] F.I.M. Craik, R.S. Lockhart, Levels of processing: a framework for memory research, J. Verbal Learn. Verbal Behav. 11 (1972) 671-684.

[12] S. Dehaene, M.I. Posner, D.M. Tucker, Localization of a neural system for error detection and compensation, Psychol. Sci. 5 (1994) $303-305$

[13] D.I. Donaldson, M.D. Rugg, Recognition memory for new associations: electrophysiological evidence for the role of recollection, Neuropsychologia 36 (1998) 377-395

[14] D.I. Donaldson, M.D. Rugg, Event-related potential studies of associative recognition and recall: electrophysiological evidence for context dependent retrieval processes, Cogn. Brain Res. 8 (1999) 1-16.

[15] E. Donchin, M. Fabiani, The use of event-related brain potentials in the study of memory: is P300 a measure of event distinctiveness? in: J.R. Jennings, M.G.H. Coles (Eds.), Handbook of Cognitive Psychophysiology: Central and Automatic System Approaches, Wiley, Chichester, 1991, pp. 471-498.

[16] E. Düzel, A.P. Yonelinas, G.R. Mangun, H.J. Heinze, E. Tulving, Event-related brain potential correlates of two states of conscious awareness in memory, Proc. Natl. Acad. Sci. 94 (1997) 5973-5978.

[17] E. Düzel, R. Cabeza, T.W. Picton, A.P. Yonelinas, H. Scheich, H.J. Tulving, E. Tulving, Task-related and item-related brain processes of memory retrieval, Proc. Natl. Acad. Sci. 96 (1999) 1794-1799.

[18] M. Fabiani, E. Donchin, Encoding processes and memory organization: a model of the von Restorff effect, J. Exper. Psychol., Learn., Mem., Cogn. 21 (1995) 224-240.

[19] M. Falkenstein, J. Hohnsbein, J. Hoormann, L. Blanke, Effects of errors in choice reaction tasks on the ERP under focused and divided attention, in: C.H.M. Brunia, A.W.K. Gaillard, A. Kok (Eds.), Phychophysiological Brain Research, Tilburg University Press, Tilburg, 1990, pp. $192-195$.

[20] M. Falkenstein, J. Hohnsbein, J. Hoormann, Event-related potential correlates of errors in reaction tasks, in: G. Karmos, M. Molnár, V. Csépe, I. Czigler, J.E. Desmedt (Eds.), Perspectives of Event-Related Brain Potentials Research (EEG supplement 44), Elsevier, Amserdam, 1995, pp. 287-296.

[21] P.D. Fletcher, C.D. Frith, M.D. Rugg, The functional neuroanatomy of episodic memory, Trends Neurosci. 20 (1997) 213-218.

[22] W.J. Gehring, B. Gross, M.G.H. Coles, D.E. Meyer, E. Donchin, A neural system for error detection and compensation, Psychol. Sci. 4 (1993) 385-390.

[23] W.J. Gehring, M.G.H. Coles, D.E. Meyer, E. Donchin, A brain potential manifestation of error-related processing, in: G. Karmos, M. Molnár, V. Csépe, I. Czigler, J.E. Desmedt (Eds.), Perspectives of Event-Related Brain Potentials Research (EEG supplement 44), Elsevier, Amserdam, 1995, pp. 261-272. 
[24] W.J. Gehring, D.E. Fencsik, Functions of the medial frontal cortex in the processing of conflict and errors, J. Neurosci. 21 (2001) $9430-9437$.

[25] H. Gemba, K. Sasaki, V.B. Brooks, 'Error' potentials in limbic cortex (anterior cingulate area 24) of monkeys during motor learning, Neurosci. Lett. 70 (1986) 223-227.

[26] R.N. Henson, M.D. Rugg, T. Shallice, O. Josephs, R.J. Dolan, Recollection and familiarity in recognition memory: an event-related functional magnetic resonance imaging study, J. Neurosci. 19 (1999) $3962-3972$.

[27] R.N. Henson, T. Shallice, R.J. Dolan, Right prefrontal cortex and episodic memory retrieval: a functional MRI test of the monitoring hypothesis, Brain 122 (1999) 1367-1381.

[28] R.N. Henson, M.D. Rugg, T. Shallice, R.J. Dolan, Confidence in recognition memory for words: dissociating right prefrontal roles in episodic retrieval, J. Cogn. Neurosci. 12 (2000) 913-923.

[29] M. Herrmann, M. Rotte, C. Grubich, A.D. Ebert, K. Schiltz, T.F. Münte, H.J. Heinze, Control of semantic interference in episodic memory retrieval is associated with an anterior cingulate-prefrontal activation pattern, Hum. Brain Mapp. 13 (2001) 94-103.

[30] D.H. Holding, Repeated errors in motor learning, Ergonomics 13 (1970) $727-734$.

[31] N.M. Hunkin, E.J. Squires, A.J. Parkin, J.A. Tidy, Are the benefits of errorless learning dependent on implicit memory? Neuropsychologia 36 (1998) 25-36.

[32] J.R. Jennings, C.C. Wood, The e-adjustment procedure for repeatedmeasures analysis of variance, Psychophysiology 13 (1976) 277-278.

[33] M.K. Johnson, C.L. Raye, Reality monitoring, Psychol. Rev. 88 (1981) 67-85.

[34] M.K. Johnson, S. Hashtroudi, D.S. Lindsay, Source monitoring, Psychol. Bull. 114 (1993) 3-28.

[35] R.S. Jones, C.B. Eayrs, The use of errorless learning procedures in teaching people with a learning disability: a critical review, Ment. Handicap Res. 5 (1992) 204-212.

[36] A. Koriat, M. Goldsmith, Monitoring and control processes in the strategic regulation of memory accuracy, Psychol. Rev. 103 (1996) 490-517.

[37] P. Luu, D.M. Tucker, Regulating action: alternating activation of midline frontal and motor cortical networks, Clin. Neurophysiol. 112 (2001) 1295-1306.

[38] P. Luu, T. Flaisch, D.M. Tucker, Medial frontal cortex in action monitoring, J. Neurosci. 20 (2000) 464-469.

[39] R.E. Mark, M.D. Rugg, Age effects on brain activity associated with episodic memory retrieval. An electrophysiological study, Brain 121 (1998) 861-873.

[40] G. McCarthy, C.C. Wood, Scalp distributions of event-related potentials: an ambiguity associated with analysis of variance models, Electroencephalogr. Clin. Neurophysiol. 62 (1985) 203-208.

[41] A. Mecklinger, Interfacing mind and brain: a neurocognitive model of recognition memory, Psychophysiology 37 (2000) 565-582.

[42] M. Moscovitch, Confabulations and the frontal systems: strategic versus associative retrieval in neuropsychological theories of memory, in: H.L. Roediger, F.I.M. Craik (Eds.), Varieties of Memory and Consciousness: Essays in Honour of Endel Tulving. Hillsdale, Lawrence Erlbaum Associates, Hillsdale, NJ, 1989, pp. $133-160$.

[43] M. Moscovitch, Confabulation, in: D.L. Schacter (Ed.), Memory Distortion. How Minds, Brains, and Societies Reconstruct the Past, Harvard University Press, Cambridge, 1995, pp. 226-251.

[44] D. Nessler, A. Mecklinger, ERP correlates of true and false recognition after different retention delays: stimulus- and response-related processes, Psychophysiology 40 (2003) 146-159.

[45] D.A. Norman, D.G. Bobrow, Descriptions: an intermediate stage in memory retrieval, Cogn. Psychol. 11 (1979) 107-123.

[46] K.A. Paller, M. Gross, Brain potentials associated with perceptual priming versus explicit remembering during the repetition of visual word-form, Neuropsychologia 36 (1998) 559-571.
[47] K.A. Paller, M. Kutas, Brain potentials during memory retrieval provide neurophysiological support for the distinction between conscious recollection and priming, J. Cogn. Neurosci. 4 (1992) $375-391$.

[48] K.A. Paller, M. Kutas, H.K. McIsaac, Monitoring conscious recollection via the electrical activity of the brain, Psychol. Sci. 6 (1995) $107-111$.

[49] K.A. Paller, M. Kutas, H.K. McIsaac, An electrophysiological measure of priming of visual word-form, Conscious. Cogn. 7 (1998) $54-66$.

[50] C. Papagno, A. Baddeley, Confabulation in a dysexecutive patient: implication for models of retrieval, Cortex 33 (1997) 743-752.

[51] D.C. Prather, Trial-and-error versus errorless learning: training, transfer and stress, Am. J. Psychol. 84 (1971) 377-386.

[52] C. Raganath, K.A. Paller, Frontal brain potentials during recognition are modulated by requirements to retrieve perceptual detail, Neuron 22 (1999) 605-613.

[53] P.W. Robinson, R.H. Storm, Effects of error and errorless discrimination acquisition on reversal learning, J. Exp. Anal. Behav. 29 (1978) $517-525$.

[54] A. Rodriguez-Fornells, A.R. Kurzbuch, T.F. Münte, Time course of error detection and correction in humans: neurophysiological evidence, J. Neurosci. 22 (2002) 9990-9996.

[55] H.L. Roediger, K.B. McDermott, Distortions of memory, in: F.I.M. Craik, E. Tulving (Eds.), The Oxford Handbook of Memory, Oxford Univ. Press, Oxford, 2000, pp. 149-164.

[56] M.D. Rugg, A.M. Schloerscheidt, M.C. Doyle, C.J. Cox, G.R. Patching, Event-related potentials and the recollection of associative information, Cogn. Brain Res. 4 (1996) 297-304.

[57] M.D. Rugg, R.E. Mark, P. Walla, A.M. Schloerscheidt, C.S. Birch, K. Allan, Dissociation of the neural correlates of implicit and explicit memory, Nature 392 (1998) 595-598.

[58] M.D. Rugg, P. Walla, A.M. Schloerscheidt, P.C. Fletcher, C.D. Frith, R.J. Dolan, Neural correlates of depth of processing effects on recollection: evidence from brain potentials and positron emission tomography, Exp. Brain Res. 123 (1998) 18-23.

[59] M.D. Rugg, L.J. Otten, R.N. Henson, The neural basis of episodic memory: evidence from functional neuroimaging, Philos. Trans. R. Soc. Lond., B Biol. Sci. 357 (2002) 1097-1110.

[60] T.F. Sanquist, J.W. Rohrbaugh, K. Syndulko, D.B. Lindsley, Electrocortical signs of levels of processing: perceptual analysis and recognition memory, Psychophysiology 17 (1980) 568-576.

[61] M.K. Scheffers, M.G.H. Coles, Performance monitoring in a confusing world: error-related brain activity, judgments of response accuracy, and types of errors, J. Exp. Psychol. Hum. Percept. Perform. 26 (2000) $141-151$.

[62] A. Schnider, R. Ptak, Spontaneous confabulators fail to suppress currently irrelevant memory traces, Nat. Neurosci. 2 (1999) 677-681.

[63] A.J. Senkfor, C. Van Petten, Who said what? An event-related potential investigation of source and item memory, J. Exper. Psychol., Learn., Mem., Cogn. 24 (1998) 1005-1025.

[64] T. Shallice, The origin of confabulations, Nat. Neurosci. 2 (1999) $588-590$.

[65] T. Shallice, P.C. Fletcher, C.D. Frith, P. Grasby, R.S. Frackowiak, R.J. Dolan, Brain regions associated with acquisition and retrieval of verbal episodic memory, Nature 368 (1994) 633-635.

[66] R.N. Singer, To err or not to err: a question for the instruction of psychomotor skills, Rev. Educ. Res. 47 (1977) 479-498.

[67] M.E. Smith, Neurophysiological manifestations of recollective experience during recognition memory judgments, J. Cogn. Neurosci. 5 (1993) $1-13$.

[68] J.G. Snodgrass, J. Corwin, Pragmatics of measuring recognition memory: applications to dementia and amnesia, J. Exp. Psychol. Gen. 117 (1988) 34-50.

[69] E.J. Squires, N.M. Hunkin, A.J. Parkin, Memory notebook training in a case of severe amnesia: generalising from paired associate learning to real life, Neuropsychol. Rehabil. 6 (1996) 55-65. 
[70] E.J. Squires, N.M. Hunkin, A.J. Parkin, Errorless learning of novel associations in amnesia, Neuropsychologia 35 (1997) 1103-1111.

[71] D.T. Stuss, M.P. Alexander, C.L. Palumbo, L. Buckle, L. Sayer, J. Pogue, Organizational strategies with unilateral or bilateral frontal lobe injury in word learning tasks, Neuropsychology 8 (1994) $355-373$.

[72] J.A. Swets, Effectiveness of Information Retrieval Methods, Am. Doc. 20 (1969) 72-89.

[73] H.S. Terrace, Discrimination learning with and without "errors", J. Exp. Anal. Behav. 6 (1963) 1-27.

[74] V. van Veen, J.D. Cohen, M.M. Botvinick, V.A. Stenger, C.S. Carter, Anterior cingulate cortex, conflict monitoring, and levels of processing, NeuroImage 14 (2001) 1302-1308.

[75] F. Vidal, T. Hasbroucq, J. Grapperon, M. Bonnet, Is the 'error negativity’ specific to errors? Biol. Psychol. 51 (2000) 109-128.
[76] E.L. Wilding, Separating retrieval strategies from retrieval success: an event-related potential study of source memory, Neuropsychologia 37 (1999) 441-454.

[77] E.L. Wilding, M.D. Rugg, An event-related potential study of recognition memory with and without retrieval of source, Brain 119 (1996) $889-905$

[78] E.L. Wilding, M.D. Rugg, An event-related potential study of memory for words spoken aloud or heard, Neuropsychologia 35 (1997) $1185-1195$.

[79] E.L. Wilding, M.C. Doyle, M.D. Rugg, Recognition memory with and without retrieval of context: an event-related potential study, Neuropsychologia 33 (1995) 743-767.

[80] B.A. Wilson, A. Baddeley, J. Evans, Errorless learning in the rehabilitation of memory impaired people, Neuropsychol. Rehabil. 4 (1994) 307-326. 